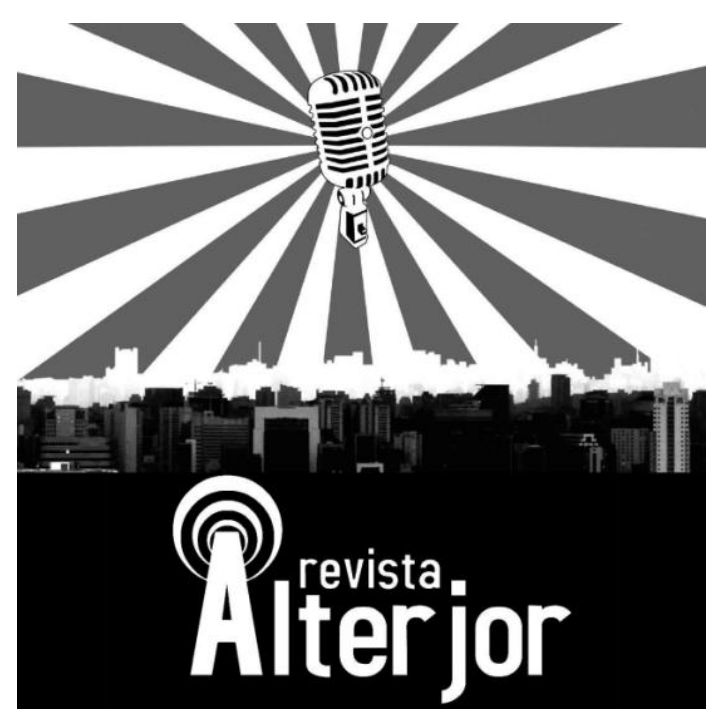

DOSSIê: "Comunicação nas Periferias"

\title{
O JORNAL BOCA DE RUA E A CONSTRUÇÃO DE TÁTICAS IDENTITÁRIAS NA COMUNICAÇÃO DE GRUPOS MINORITÁRIOS
}

\author{
Deivison Moacir Cezar de Campos ${ }^{1}$ \\ Caroline de Mendonça Musskopf ${ }^{2}$
}

RESUMO: Este estudo investiga a produção audiovisual para redes sociais do projeto Jornal Boca de Rua, desenvolvida por pessoas em situação ou vivência de rua, no período entre março e outubro de 2018, a partir das lógicas de produção de conteúdo do grupo integrante do projeto. Objetiva-se analisar as formas como esta produção atravessa a construção de identidade e de pertencimento dos integrantes do grupo. Utiliza-se da transmetodologia, que desenvolveu-se a partir de três elementos: o observado; vídeos desenvolvidos entre março e outubro de 2018; o que dizem os pessoas do grupo. Por fim, observou-se a construção e repetição de vínculos e alianças e a utilização de discursos identitários de forma tática com o objetivo de disputar espaços simbólicos, sensibilizar o público e autorrepresentar-se.

PALAVRAS-CHAVE: Comunicação. Minorias. Jornal Boca de Rua. Identidade. Autorrepresentação.

ABSTRACT: This study investigates the audiovisual production for social networks of the Jornal Boca de Rua project, developed by people in street experience or situation, between March and October 2018, thought from the logic of content production of the group that is part of the project. The objective is to analyze the ways in which this production goes through the construction of identity and belonging of the group members. It uses the trans-methodology, which developed from three elements: the observed; ten videos developed between March and October 2018; what the people in the group say. Therefore, was observed the construction and repetition of bonds and alliances and the use of identity discourses tactically in order to dispute symbolic spaces, sensitize the public and self-representation.

KEYWORDS: Communication. Minorities. Jornal Boca de Rua. Identity. Self-representation.

\footnotetext{
${ }^{1}$ Doutor em Ciências da Comunicação. Professor no PPG em Educação e cursos de Comunicação da Ulbra. https://orcid.org/0000-0001-9928-9825 E-mail: deivisondecampos@gmail.com

2 Jornalista. Analista de comunicação na UniLasalle. Bolsista PIBIC NEABI/Ulbra. https://orcid.org/0000-0002-9211-9302 E-mail: caroline.m.musskopf@gmail.com
}

Revista ALTERJOR

Grupo de Estudos Alterjor: Jornalismo Popular e Alternativo (ECA-USP)

Ano 10 Volume ol Edição 23 Janeiro-Julho de 2021

Avenida Professor Lúcio Martins Rodrig̉ues, 443, Cidade Universitária, São Paulo, CEP: 05508-020 


\section{INTRODUÇÃO}

Grupos minoritários se utilizam historicamente de suportes midiáticos para disputar espaço simbólico e produzir discursos sobre si próprios para que suas pautas ganhem visibilidade. Esse ambiente de disputa ganhou novos tensionamentos com a difusão da internet, mesmo tendo iniciado no impresso através de jornais e expressões artísticas como fanzines. Essas iniciativas possibilitaram a inserção de diferentes formas de pertencimento e seus pleitos no debate público. No entanto, alguns grupos, como o das pessoas em situação de rua, permanecem à margem da discussão sobre direitos de cidadania.

Ao contrário de outras minorias, o elemento de identificação que faz com que a população em situação de rua ${ }^{3}$ se constitua enquanto grupo, muitas vezes, é a nãoidentificação com a forma de vida imposta culturalmente como norma. O nãopertencimento normativo, nesse sentido, gera pertencimento. Se, por um lado, grande parte dessa população luta pela garantia de seus direitos fundamentais - como o de acesso à moradia, outra parcela reivindica a eficiência dos serviços de assistência social do Município para quem precisa ou opta por morar nas ruas.

Por diferentes motivos, essas pessoas vivem fora desses padrões sociais e isso acarreta consequências para seus corpos e sua existência como um todo. O ódio, a intolerância e a violência contra os grupos marginalizados têm aumentado como regra, tornando-se aspectos centrais para se entender o momento político e social atual do país. Nesse contexto, as populações historicamente marginalizadas e vulneradas (ARÁN e PEIXOTO, 2007), como a população em situação de rua, enfrentam uma potencialização dos mecanismos biopolíticos que os atingem. Uma das formas de

\footnotetext{
${ }^{3}$ Ao longo dos anos, o termo para referir-se a essa população mudou e, até hoje, há dissenso nesse quesito. Nesse sentido, ainda que o grupo do Jornal Boca de Rua denomina-se entre si como "moradores de rua", optou-se por "pessoa em situação de rua" tendo em vista o movimento de autoafirmação do Movimento Nacional da População de Rua (MNPR). Academicamente, a questão já foi debatida por diversos pesquisadores, em Porto Alegre, Patrice Schuch e Ivaldo Gehlen (p, 17, 2012) afirmam que este termo, "situação de rua", visa "combater processos de estigmatização dessa população, definindo-os a partir de uma concepção do habitar a rua como uma forma de vida possível [...]". Foi a partir de um momento histórico de militância que "expressões tais como 'povo de rua' e 'morador de rua' tiveram o intuito de reforçar a consciência de grupo" (Ibidem, p. 17, 2012). No entanto, percebeu-se ao passar do tempo que haviam várias "situações" não heterogênea em relação à permanência e experiência na rua.
} 


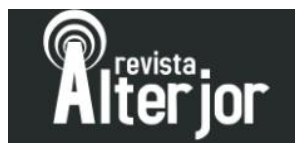

exclusão da população em situação de rua é o silenciamento quando se considera a mídia hegemônica. Nas últimas décadas, no entanto, esse grupo tem criado estratégias de visibilidade através de projetos comunicacionais, como o Jornal Boca de Rua em Porto Alegre.

O Jornal Boca de Rua existe há 18 anos e foi criado com o objetivo de ser uma plataforma que "dá voz àqueles que não são ouvidos" ". Com ênfase na população em situação de rua, o jornal começou quando as jornalistas Rosina Duarte e Clara Glock, que coordenavam o projeto, reuniram-se com um pequeno grupo de pessoas em situação de rua para produzir a edição n.1: "Vozes de uma gente invisível" . Em 2013, a manchete da primeira capa foi reutilizada em um documentário homônimo, produzido por uma produtora local com a participação e geração de renda para os integrantes do jornal que colaboraram durante o projeto.

Partindo dessas diferentes iniciativas comunicacionais, tem-se como objetivo geral desta pesquisa analisar as formas como a produção de conteúdo audiovisual para as redes sociais do Jornal Boca de Rua atravessa a construção da identidade e do pertencimento das pessoas em situação - ou vivência - de rua que atuam no grupo.

A pesquisa foi desenvolvida a partir do que se entende como uma "transmetodologia", de abordagem qualitativa e forma descritiva, conforme será descrito nos capítulos seguintes. Maldonado (2015, p. 720) aponta que uma pesquisa é transmetodológica quando parte de uma "articulação cooperativa entre métodos provenientes de vários campos de conhecimento". Propõem-se, portanto, uma transmetodologia a partir dos três eixos: observação e caderno de campo de inspiração etnográfica; análise documental e exercícios de oratórias temáticas individuais. Isto é, a análise desenvolveu-se a partir de três elementos: 1) o observado; 2) os dez vídeos desenvolvidos entre março e outubro de 2018; 3) o que dizem os participantes do grupo.

No que diz respeito ao observado, o estudo de inspiração etnográfica ocorreu

\footnotetext{
${ }^{4}$ A expressão foi utilizada pelo grupo em reunião de pauta durante o processo de observação-participante.

${ }^{5}$ Projeto patrocinado pelo programa Rumos do Itaú Cultural. Produção da Bigode de Gato (Porto Alegre) e Boulevard Filmes (Rio de Janeiro) e direção e roteiro do jornalista Marcelo Andrighetti. 2013, Duração: 10 minutos.
} 


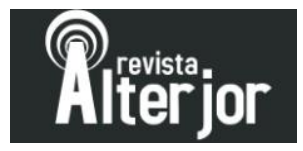

após a inserção no grupo, utilizando-se de técnicas de observação-participante desde maio de 2017 até dezembro de 2018 ${ }^{6}$. Amparou-se em Winkin (1998) para buscar a imersão no cotidiano do grupo a fim de desenvolver análises descritivas da realidade, compreendendo a cidade e suas microssociedades enquanto laboratório natural. Para o autor (Ibidem, 1998, p. 132) a etnografia: "consiste em primeiro lugar em 'saber ver'. É em seguida uma disciplina que exige saber 'estar com' [...] e por fim que se 'saiba escrever". Por isso, afirma-se uma inspiração etnográfica no sentido de observar e estabelecer padrões às regras implícitas das relações sociais dentro do Jornal Boca de Rua.

A partir da chamada análise documental, observou-se os vídeos produzidos pelo grupo principalmente em seus aspectos de comunicação não-verbal e a presença destes corpos diante da câmera. Este tipo de análise consiste em estudos "baseados em documentos como material primordial, sejam revisões bibliográficas, sejam pesquisas historiográficas, extraem deles toda a análise, organizando-os e interpretando-os segundo os objetivos da investigação proposta" (PIMENTEL, 2001, p. 180). Já por meio de uma oralidade temática, os membros do jornal que decidiram participar da pesquisa, foram gravados em áudio após serem instigados a pensar sobre suas participações no projeto e os significados do Boca de Rua em suas vivências. Portanto, completando a tríade de análise, utilizou-se de entrevistas não estruturadas, chamadas aqui de oralidade temática, isto é, a apresentação do tema e dos objetivos deste artigo para que os integrantes do grupo falassem o que lhes parecesse interessante, sendo instigados por perguntas não previamente roteirizadas.

Em um primeiro momento, apresenta-se o Jornal Boca de Rua a partir de sua história, seus suportes de produção de conteúdo e o dia a dia das reuniões semanais do grupo. Após, discute-se suas práticas táticas diárias de autoafirmação enquanto um grupo minoritário. Desse modo, analisa-se um recorte de dez vídeos curtos produzidos

\footnotetext{
${ }^{6}$ Durante este período foi mantido um diário de campo, cujas referências serão indicadas no texto sem identificação de falantes e indicado como diário. Por esse motivo, durante os trechos deste artigo que se referem a experiências em que estive muito envolvida ou à análises essencialmente subjetivas oriundas da observação-participante, utilizo-me da primeira pessoa do singular, contrariando algumas convenções acadêmicas para a escrita de artigos científicos.
} 


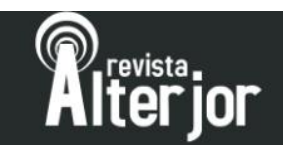

pelo grupo, refletindo sobre os processos jornalísticos observados.

\section{JORNAL BOCA DE RUA}

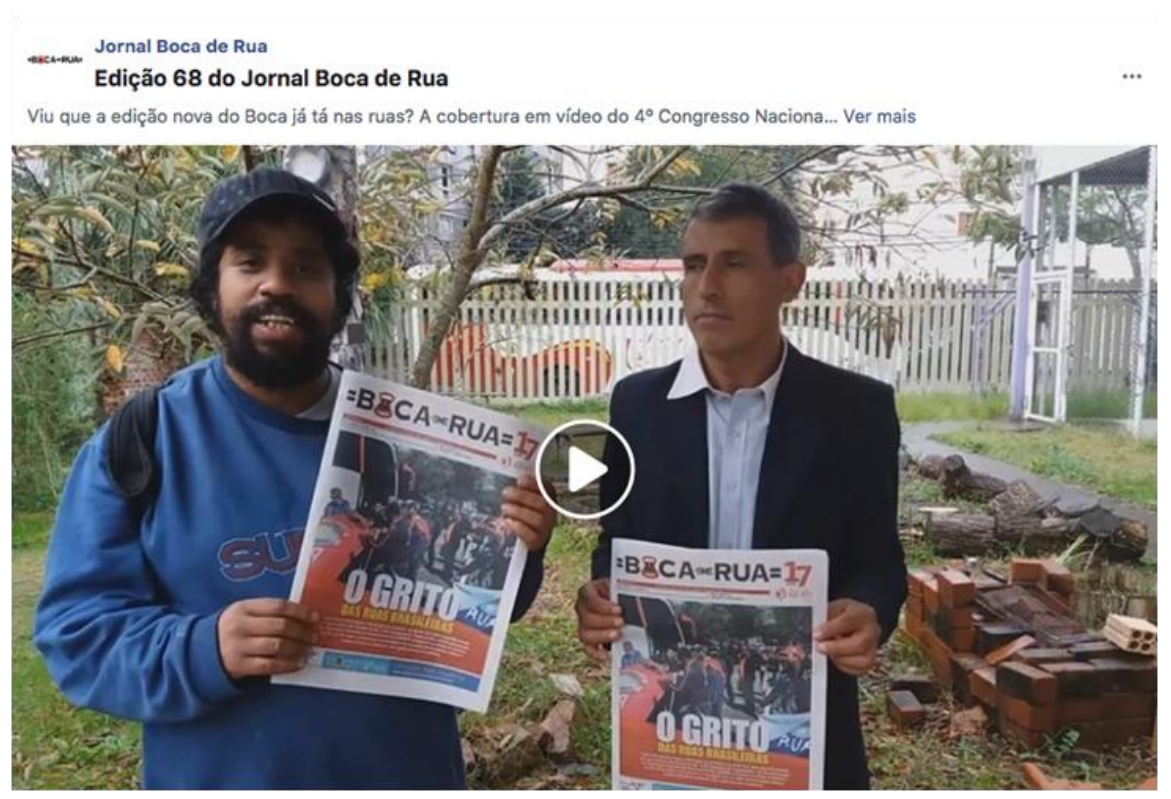

O Jornal Boca de Rua é um projeto desenvolvido com e por integrantes da

população em situação de rua de Porto Alegre, ou pessoas em situação de vulneração (ARÁN e PEIXOTO, 2007). A primeira edição do jornal impresso - número zero, foi posta em circulação em dezembro do ano 2000, apesar do projeto ter sido oficializado apenas em 2001 durante o primeiro Fórum Social Mundial de Porto Alegre. A tiragem foi financiada pelo Sindicato dos Bancários de Porto Alegre e pela Federação dos Metalúrgicos e CUT/RS até 2017. Atualmente, a tiragem trimestral conta com doações, enquanto o grupo planeja uma plataforma de crowdfunding.

Os 12 mil exemplares ${ }^{7}$ custam cerca de 4 mil reais para que sejam impressos e são vendidos por esse grupo de pessoas em situação de rua e o valor é revertido em renda, parte de uma política ideológica de redução de danos, conforme as políticas do projeto. Os 35 membros do grupo - na época - se reúnem toda terça-feira no galpão da Escola Porto Alegre - instituição municipal que atua com a alfabetização e formação de

\footnotetext{
${ }^{7}$ Durante a coleta de dados da pesquisa e participação semanal das reuniões do grupo (maio de 2017 a agosto de 2019), cada exemplar - de 14 a 18 páginas, em impressão colorida - custava 2 reais.
}

\footnotetext{
Revista ALTERJOR

Grupo de Estudos Alterjor:Jornalismo Popular e Alternativo (ECA-USP)

Ano 10 Volume Ol Edição 23 Janeiro-Junho de 202l

Avenida Professor Lúcio Martins Rodrig̉ues, 443, Cidade Universitária, São Paulo, CEP: 05508-020
} 
pessoas em situação de rua.

Tido por seus participantes como alternativo em relação aos produtos comunicacionais da mídia hegemônica, o projeto Boca de Rua é integrado também por estudantes voluntários e intergrantes da ONG Agência Livre para a Informação, Cidadania e Educação (Alice) ${ }^{8}$, que gestou o projeto. Nesse sentido, o jornal atua como um nó dentro de uma rede de comunicação cidadã, que busca, a partir de suas linhas editoriais, horizontalizar o processo de produção. O grupo inclusive desenvolveu um conjunto de regras para garantir essa horizontalidade e uma boa convivência 9 .

O projeto também busca reconhecer particularidades dos indivíduos e tirá-los da categoria comum de "morador de rua". Para Rosina Duarte (SCHUCH et al, 2017, p. 201), coordenadora do projeto, "o fato de terem a oportunidade de se expressar sem intermediários externos os torna parte integrante de uma sociedade que os excluiu, colocando-os como sujeitos da sua história". Nesta mesma perspectiva, observa-se que este espaço colaborativo de produção de conteúdo funciona como prática de redução de $\operatorname{dados}^{10}$.

O Jornal Boca de Rua não é subversivo apenas em intencionalidade e produção de conteúdo, mas torna-o em sua existência e resistência de atuação. Isso porque a violência institucionalizada contra a população em situação de rua tem aumentado com o passar dos anos, o que gerou inclusive o desenvolvimento de uma edição completa do Jornal Boca de Rua sobre o extermínio da população em situação de rua - edição 63, "Luto e Luta":

\footnotetext{
8 A Organização Não Governamental gaúcha Agência Livre para Informação, Cidadania e Educação (Alice) desenvolve projetos comunicacionais que visam afastar-se dos discursos presentes na mídia hegemônica sobre grupos tidos como minoritários. Há voluntários da Alice que não conseguem frequentar as reuniões do Boca de Rua mas participam de forma "invisível" dentro de processos como a diagramação, a arrecadação de fundos e mesmo a organização do material quando impresso pela gráfica.

${ }^{9}$ Em função do limite de páginas para este artigo, optou-se por utilizar de um link externo para disponibilizar as regras de convivência do Jornal Boca de Rua. Disponível em: $<$ https://bit.ly/3227WHM>

${ }^{10}$ Redução de Danos consiste em práticas e/ou políticas públicas voltadas para usuários de drogas, a partir da "construção de Projetos Terapêuticos que aumentem o grau de liberdade, autonomia e corresponsabilidade, tendo como foco estimular a reflexão sobre a relação com o uso de drogas, bem como o aprendizado e cuidado conjunto e compartilhado" (COMPOSIÇÕES DE REDUÇÃO DE DANOS, 2019).
} 
Paulo Ricardo Camargo de Oliveira foi assassinado no dia 21 de março com vários tiros pelas costas em pleno dia, na praça da Matriz lotada de frequentadores, cercada por câmeras de segurança [...] Poucos minutos após o crime, antes de ouvir qualquer testemunha, o tenente coronel Eduardo Amorim, da Brigada Militar, [...] declarou não descartar a hipótese de ser um acerto de contas do tráfico (MORTE AO VIVO, 2017, p. 3).

Segundo dados do Ministério da Saúde de 2019, foram mais de 17 mil casos de violência contra pessoas em situação de rua nos últimos 3 anos (FIGUEIREDO, 2019). Estes dados são observáveis na mudança do dia a dia das pessoas em situação de rua e foram citadas em entrevista para esta pesquisa:

Hoje em dia a diferença é grande, de 6 anos pra cá a diferença é bem grande. [...] Hoje eu não vejo mais a segurança em grupos, vejo mais a segurança individual. Isso por diversas situações. Até mesmo pelo momento que se vive no Brasil hoje né. O momento lá em cima... reflete aqui. [...] antes a gente tinha mais acolhimento, hoje em dia você não tem. Tinha mais locais de referência, hoje não tem. Então isso por si acaba fazendo também com que aumente a violência com o povo da rua até mesmo entre si. [...] Isso também acaba deixando as pessoas mais revoltadas. Por si só o povo que vive na rua já tem uma revolta, já traz alguma coisa. Aí aquilo ali vai acumulando muitas coisas e por isso que então muitas vezes usam... os governantes usam isso aí pra justificar aquela história de internação compulsória ou muita coisa que seja tratada a partir de medicação. No meu ponto de vista é esse o reflexo que se tem. Antes eu me sentia seguro com um montão de gente, hoje me sinto mais seguro e tranquilo vivendo sozinho (Z., 2019).

Com a produção de conteúdo centralizada no jornal impresso, há também um blog, alimentado apenas pelos colaboradores, que funciona como arquivo das capas e manchetes do jornal, mas que não é mais atualizado desde maio de 2017. No final de 2018, o grupo passou a produzir com maior frequência vídeos para as redes sociais.

No jornal comemorativo em alusão aos 18 anos de Boca, seus integrantes afirmam não ser mais apenas 'boca da rua', mas olhos e ouvidos também. A manchete da edição de n. 70 refere que o jornal: "Nos seus 18 anos de vida se tornou um canal, uma ponte, um tradutor de ruaologia”. O termo cunhado pelo grupo, ruaologia, se refere 


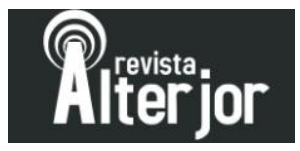

aos conhecimentos adquiridos empiricamente por essa minoria que possui "vivência de rua"; isto é, que já estiveram ou estão em situação de rua. Há, portanto, indícios de pertencimentos e formação de táticas identitárias na criação deste conceito, ruaologia, como busca pela equivalência entre os conhecimentos desenvolvidos na rua e os conhecimentos desenvolvidos na academia. Essa "ciência da rua" mostra como o jornal e, de forma mais abrangente, a comunicação das minorias, representa também uma possibilidade de reconhecimento dessa forma de aprender com o mundo.

Sodré (2005, p. 13) afirma que minoria se caracteriza por "um lugar onde se animam os fluxos de transformação de uma identidade ou de uma relação de poder". A partir desta perspectiva, um grupo hegemônico é aquele dominado pelo consenso, enquanto um grupo minoritário é um dispositivo simbólico de recusa ao consentimento de existir. As características básicas, portanto, de um grupo minoritário são: 1) vulnerabilidade jurídico-social; 2) identidade in statu nascendi, isto é, a minoria vive de um eterno recomeço e transformação identitária; 3) luta contra hegemônica; 4) estratégias discursivas e de ações demonstrativas, como atos públicos, campanhas e jornais (SODRÉ, 2005). Ao abordar a construção de uma comunicação das minorias, Paiva (2005, p. 21-22) escreve que:

\footnotetext{
Apesar de a forma social estar marcada pela violência, os grupos minoritários podem optar por adotar formas de ação capazes de fazer frente à crueldade institucionalizada e generalizada com projetos sociais inclusivo que priorizem a existência harmônica entre os cidadãos (PAIVA, 2005, p. 21-22).
}

Considera-se ainda o contexto história no qual o projeto foi criado, durante uma efervescência de movimentos sociais em Porto Alegre. Isso porque o fato dele continuar tão ativo em 2019, inclusive reinventando-se a partir dos formatos de produção, destaca justamente o motivo de existência da comunicação de minorias: "[...] minoria é uma recusa de consentimento, é uma voz de dissenso em busca de uma abertura contrahegemônica no círculo fechado das determinações societárias" (SODRÉ, 2005, p. 14).

Observa-se, portanto, que os membros do Jornal Boca de Rua mobilizam-se por 


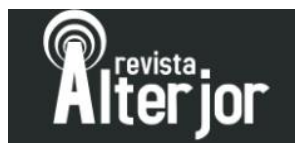

meio deste instrumento que, conforme os autores, constituiria uma "comunicação das minorias". O grupo também se propõe a pautar assuntos referentes, em um primeiro momento, a outros marcadores da diferença de forma interseccional, como, mais recentemente, as mulheres trans em situação de rua que passaram a integrar o grupo questão presente na edição n. $71^{11}$ do jornal.

As reuniões de pauta do jornal Boca de Rua, ainda que frequentemente centralizadas em discussões internas em forma de "informes", são fundamentais para o entendimento das problemáticas de "identidade" e "pertencimento" no que diz respeito às pessoas participantes desta pesquisa.

\section{DA PRODUÇÃO DE NOTÍCIAS ÀS TÁTICAS COTIDIANAS}

Durante os anos de observação-participante nas reuniões de pauta semanais do Jornal Boca de Rua, foi possível identificar a intenção de um padrão nos processos de produção de conteúdo que na prática acaba geralmente subvertido. $\mathrm{O}$ produto principal do grupo é o jornal impresso, considerando sua possibilidade concreta e viável de monetização. Explica-se, nesse sentido, o porquê da organização de pauta ser voltada quase exclusivamente para a produção neste formato.

Um dos integrantes foi enfático ao dizer: "o que me faz vir é o dinheiro né?" (P., 2019); outro, corroborou, de certa forma, com esta perspectiva ao afirmar que "o Boca paga o meu aluguel" (DIÁRIO, ago, 2019). Em sua fala, no entanto, houve um agradecimento implícito. Observa-se ainda a (des)vinculação do Jornal Boca de Rua com o Movimento Nacional da População em Situação de Rua (MNPR): "O Boca não é um movimento, ele é um grupo de trabalho, onde a gente reivindica as nossas necessidades [...] E o Movimento Nacional da População de Rua é uma luta pelas causas, entende? [...] A única diferença é que é um propósito diferente" (Z., 2019).

\footnotetext{
${ }^{11}$ Considerando apenas os dois anos em que estive ativa no grupo, foi apenas no final de 2018 que presenciei a aproximação desta população (trans), o que inclusive gerou alguns tensionamentos nas relações do grupo - já que no início pareceu haver o estranhamento de alguns integrantes. Há, no entanto, relatos da presença de outras mulheres trans no decorrer da história do jornal.
} 


\title{
Ritiejor
}

A centralidade da monetização do jornal pode ser observada também quando os integrantes do grupo respondem sobre o processo jornalístico no qual estão inseridos. É possível sugerir que não é claro para eles qual é a parte jornalística de fato da produção do jornal. No entanto, é evidente a vinculação afetiva, o papel educador e os processos de construção de táticas identitárias presentes na produção do Jornal Boca de Rua:

\begin{abstract}
A gente vende o nosso Boca pras pessoas, assim ó: eu to com o jornal, aí a pessoa não quer, eu não preciso forçar a pessoa. [...] Como eu vou te explicar? A lição do Boca é a nossa dos morador de rua, a gente escreve, a gente faz a história, a gente faz a roda pra ver qualé vai botar no jornal, conversa... (silêncio) É importante porque é bom pros morador de rua também saber do jornal também. Porque uns não sabem, mas a gente esclarece com o jornal Boca de Rua. (B., 2019).
\end{abstract}

A organização temporal de uma reunião de pauta no período do acompanhamento acontecia em dois momentos. Em um primeiro, o grupo se reúne para "informes" - algum relato de acontecimento relevante, programação voltada para a população de rua, algum evento com temática adjacente ao jornal, informação sobre algum membro ou ex-membro do grupo, etc. A partir desses informes, muitas vezes surgem pautas cujas matérias são veiculadas na edição seguinte. Na segunda parte, há duas possibilidades; ou os participantes se dividem em pequenos grupos, cada um responsável por uma pauta previamente decidida, ou há o que o grupo denomina como debate Boca.

Dentro do processo jornalístico convencional, esse primeiro momento de informes e escolha de pautas pode ser entendido a partir da Teoria do Gatekeeper. Traquina (2008, p. 150) a define a partir da seguinte lógica:

[...] o processo de produção da informação é concebido como uma série de escolhas onde o fluxo de notícias tem de passar por diversos gates, isto é, "portões" que não são mais do que áreas de decisão em relação às quais o jornalista [...] tem que decidir se vai escolher essa notícia ou não. 
Essa decisão entre o que é um fato e o que é um fato noticioso e portanto passível de tornar-se notícia, ainda que este processo esteja completamente envolto das subjetividades dos atores sociais envolvidos, ampara-se em valores-notícia. Para Wolf (2003), os principais valores-notícia são: morte, notoriedade, proximidade, relevância, novidade, tempo ou atualidade, notabilidade, inesperado, conflito ou controvérsia, infração e escândalo.

São pautas recorrentes no dia a dia do jornal: projetos de geração de renda, atividades do Movimento Nacional da População em Situação de Rua, reivindicações de melhorias para os aparelhos de assistência social do Município, institucionalizados ou não - como a $\operatorname{Fasc}^{12}$, o Caps $^{13}$, o Centro Pop I e II ${ }^{14}$, o Bandejão ${ }^{15}$ e as iniciativas chamadas genericamente de "sopão". Além disso, a rede de apoio do Boca de Rua é formada por outras mídias contra-hegemônicas de Porto Alegre, Organizações Não Governamentais como o Ilê Mulher ${ }^{16}$ e o restaurante Germina ${ }^{17}$, por iniciativas

${ }^{12}$ Fasc é sigla para Fundação de Assistência Social e Cidadania e "é o órgão gestor da Política de Assistência Social no Município de Porto Alegre, responsável pela oferta de serviços, programas e benefícios que promovam a inclusão de cidadãos, famílias e grupos que se encontram em situação de vulnerabilidade e risco social" (APRESENTAÇÃO, 2019).

${ }^{13}$ O Centro de Atenção Psicossocial é um programa Municipal de Porto Alegre que existe com o objetivo de realizar o "acompanhamento de pessoas com problemas de saúde mental graves e persistentes como a esquizofrenia, trastorno esquizoafetivo, trastorno bipolar, autismo e uso de drogas, com atendimento feito por equipe multiprofissional" (CENTRO DE ATENÇÃO PSICOSSOCIAL, 2019).

${ }^{14}$ O Centro de Referência Especializado para Pessoas em Situação de Rua faz parte dos programas de atendimento da Fasc e o site da Prefeitura de Porto Alegre o define como um espaço que "promove atendimento social com equipe multidisciplinar para adultos, idosos e famílias em situação de rua, de forma individualizada e coletiva, durante o período do dia, propondo aos usuários alternativas de enfrentamento à situação de rua e encaminhamentos junto a rede de serviços. Porto Alegre conta com dois Centros Pop" (CENTRO POP, 2019).

${ }^{15}$ O Restaurante Popular de Porto Alegre encerrou o atendimento no dia 9 de maio de 2019 - na época oferecia 500 refeições por dia. No dia 14 do mesmo mês, após certa pressão popular, a Secretaria Municipal de Desenvolvimento Social e Esporte anunciou um "bandejão provisório" no Ginásio Tesourinha com menos de 200 refeições por dia que foram distribuídas apenas para pessoas cadastradas previamente junto a órgãos da Prefeitura. A medida provisória ainda estava em vigor durante o fechamento deste texto, em setembro de 2019.

${ }^{16}$ A Associação Cultural e Beneficente Ilê Mulher é frequentemente - exemplos na edição 63 (p. 11, abril, maio e jun, 2017) e na edição 66 (p. 12, jan, fev e mar, 2018) - apontada como uma alternativa em relação aos albergues, abrigos e serviços de assistência social Municipal como um todo.

${ }^{17}$ O Germina é um "coletivo de pessoas que têm um restaurante vegano autogestionado" (JORNAL BOCA DE RUA, edição 66, p. 10). A partir do envolvimento pessoal de um dos integrantes do coletivo com o Movimento Nacional da População de Rua, o Germina virou um espaço de geração de renda e

Revista ALTERJOR

Grupo de Estudos Alterjor:Jornalismo Popular e Alternativo (ECA-USP)

Ano 10 Volume ol Edição 23 Janeiro-Junho de 2021

Avenida Professor Lúcio Martins Rodrig̉ues, 443, Cidade Universitária, São Paulo, CEP: 05508-020 


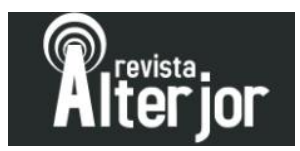

quaisquer que atuem com a população em situação de rua, além das pessoas em geral que voluntariamente se colocam como colaboradores da causa social como um todo que engloba a População de Rua.

Quando se fala em comunicação das minorias, como o caso do Jornal Boca de Rua, tende-se a direcionar estes valores-notícia para a população em questão. Isto é, se em outro jornal a morte de uma pessoa em situação de rua não é notícia por falta de interesse público, no Jornal Boca de Rua há uma edição inteira sobre o extermínio de pessoas e o aumento da violência contra pessoas em situação de rua nos últimos anos. Há, ainda, um movimento de lembrar e fazer estas mortes presentes nas reuniões do grupo:

Ricardo comunica ao grupo o falecimento do Índio, que participou do Boca de Rua por muitos anos mas estava afastado recentemente. [...] "Quem for mais próximo do Índio, por favor, fala um pouco sobre ele". Ricardo é o primeiro a se manifestar e conta que "ele sempre falava bonito, sempre fez parte da família e nunca se afastou totalmente". André o complementa dizendo que "ele era meio ranzinza, doente pelo Grêmio e metido a guri" (DIARIO, out, 2017).

Com isso, o grupo reafirma que, contrariando a cobertura dos veículos hegemônicos, nas páginas do Jornal Boca de Rua, a morte de uma pessoa em situação de rua não passa despercebida. A noticiabilidade, portanto, é definida a partir de critérios diferentes aos hegemônicos. Afinal, quando se lembram e falam sobre quem foi o outro, falam também, de certa forma, sobre quem eles próprios são e garantem que também não serão esquecidos entre os seus.

Em uma das produções em vídeo do grupo, realizam uma entrevista com a família de um membro antigo do Jornal Boca de Rua já falecido. O entrevistador, integrante do jornal, pede apenas para que a mãe do C. fale sobre ele. Ao final, faz de improviso uma pequena poesia. Ao fazê-lo, Z. expressa sua vontade de vincular-se aos

emprego para o "povo da rua". Atualmente, alguns integrantes do Jornal Boca de Rua também trabalham no local, fazendo com que haja flexibilidade de horário em momentos de intersecção das atividades dos dois grupos.

Revista ALTERJOR

Grupo de Estudos Alterjor: Jornalismo Popular e Alternativo (ECA-USP)

Ano 10 Volume ol Edição $23 \quad$ Janeiro-Junho de 2021

Avenida Professor Lúcio Martins Rodrig̉ues, 443, Cidade Universitária, São Paulo, CEP: 05508-020 


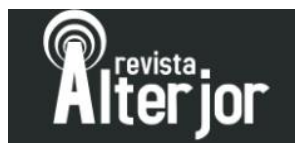

espaços e símbolos artísticos, à poesia marginal - a exemplo dos movimentos de slam, campeonatos de poesia de rua - e, portanto, ao conhecimento.

Há a indicação também de como os participantes do Jornal Boca de Rua entendem a comunicação, isto é, a comunicação enquanto toda expressão cultural. Em outros momentos, poesias, grafites e desenhos também foram publicados no jornal impresso, com as devidas autorias das obras. A identidade destas pessoas e, portanto, deste projeto, é construída também a partir destes elementos. A movimentação corporal diferencia o entrevistador da entrevistada, assim como a "presença" no vídeo, já que Z. fala com mais naturalidade e toda a atenção de quem assiste.

As práticas dos participantes do Jornal Boca de Rua, nesse contexto, podem ser entendidas a partir do que Certeau (1998) define como tática. Para o autor (CERTEAU, 1998), tática é a prática que ocorre a partir de tudo que tensiona uma lógica de "passividade". Isso porque, "mesmo subjulgados, alguns grupos utilizam-se das práticas, leis e representações negativas para outros fins" (Ibidem, p. 94-95) que não aqueles originais. A partir dessa perspectiva, outras intencionalidades podem subverter processos de repressão "a partir de dentro - não rejeitando-as ou transformando-as [...] [estes grupos] metaforizam a ordem dominante: faziam-na funcionar em outro registro". Certeau (1998, p. 92-93) explica ainda que, assim como existem diferentes "maneiras de escrever", há também diferentes maneiras de "fazer" que podem ser operacionalizadas. Assim, práticas do cotidiano podem ser utilizadas de maneira tática. Ele elucida:

[...] a tática é movimento 'dentro do campo de visão do inimigo', como dizia von Bullow, e no espaço por ele controlado. [..] ela opera golpe por golpe, lance por lance. [...] tem que utilizar, vigilante, as falhas que as conjunturas particulares vão abrindo na vigilância do poder proprietário. [...] em suma, a tática é a arte do fraco (CERTEAU, 1998, p. 100).

Pode-se entender como tático, no sentido de tensionamento da distribuição de forças, a reivindicação do grupo por espaços representativos - tanto discursivos, como físicos, em universidades por exemplo - o modo como se relacionam entre si e com os voluntários que atuam no projeto, ou mesmo as formas como reivindicam melhorias nos 


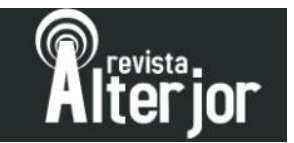

equipamentos de assistência social do Município: por meio do jornal, em conteúdos jornalísticos.

\section{CONSTRUÇÃO DE IDENTIDADE E PERTENCIMENTO}

O conceito e a problemática da identidade vêm sendo discutidos nas últimas décadas a fim de entender este processo de construção constante e sobreposições. Para Stuart Hall (2006, p. 7): "as velhas identidades, que por tanto tempo estabilizaram o mundo social, estão em declínio, fazendo surgir novas identidades e fragmentando o indivíduo moderno, até aqui visto como um sujeito unificado". Para o autor, as identidades - resultado do processo de perceber-se e ser percebido culturalmente - são sobrepostas e muitas vezes contraditórias.

Nesse sentido, a comunicação pode exercer um papel essencial para que determinadas identidades sejam reafirmadas e para que constitua-se uma noção de pertencimento (HALL, 2006). A partir de uma perspectiva similar, Bauman (2005 p. 17) analisa que:

Tornamo-nos conscientes de que o 'pertencimento' e a 'identidade' não tem a solidez de uma rocha, não são garantidos para toda a vida, são bastante negociáveis e revogáveis, e de que as decisões que o próprio indivíduo toma, os caminhos que percorre, a maneira como age [...] são fatores cruciais tanto para o 'pertencimento' quanto para a 'identidade'.

Para o autor, são os "deslocamentos" que provocam que cada um repense a questão do pertencimento de modo a tirar deste conceito o peso essencialista que carrega. E o que nos distingue como pessoas é como lidamos com essas questões. Somos o resultado dessas negociações que, para Bauman, permanecem "eternamente pendente[s]". Ainda assim, Bauman (2005, p. 25) destaca que: "[...] perguntar 'quem você é?' só faz sentido se você acredita que possa ser outra coisa além de você mesmo; só se você tem uma escolha, e só se o que você escolhe depende de você [...]". 


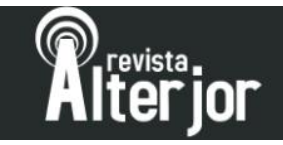

A partir das obras de Hall (2006), Bauman (2005) e Certeau (1998) utiliza-se a denominação de táticas identitárias para analisar os conteúdos audiovisuais e as práticas relativas a ele dentro do contexto do Jornal Boca de Rua. Táticas identitárias, portanto, seriam a utilização do que Certeau (1998) definiu como tática para afirmar e representar os processos de construção identitária. Ao mesmo tempo, agindo de forma estratégica para disputar espaço na esfera pública, visibilidade e possibilidades de autorrepresentação.

Alvarenga e Hikiji (2006, p. 197) analisam que para o filme está dentro dessa categoria de autorrepresentação quando o autor possui experiências compartilhadas pelos membros do grupo que está sendo retratado ou de fato faça parte do grupo, quando o tema do vídeo é o tema da sua própria vida. Desse modo, pode-se entender a produção audiovisual analisada como uma construção compartilhada com os integrantes do Jornal no sentido de que as decisões sobre como e onde filmar dependia deles, ainda que a edição do material não.

Nesse mesmo contexto, Araújo (2015, p. 23-24) traz o conceito de autoetnografia para a produção audiovisual e o traduz como a etnografia desenvolvida por grupos minoritários e não apenas sobre eles. $\mathrm{O}$ autor aponta que:

\footnotetext{
A apropriação da câmera pelos sujeitos até então somente por ela observados está no cerne da produção audiovisual de não-ficção contemporânea, na medida em que a alteridade [...] teve o seu local de referência deslocado, e passou a ser não mais apenas retratada audiovisualmente, mas, sobretudo, a realizar suas próprias filmagens (ARAÚJO, p. 72, 2015).
}

De forma complementar, Azevedo (2017, s/p) destaca ainda que: "Na imagem em movimento, o contar de si tem uma potência específica, sobretudo quando se trata de um contar de si numa relação com outros ou com outros temas: deixa entender a fragilidades do autor perante o espectador, dando-lhe espaço para identificar-se ou questioná-las". 


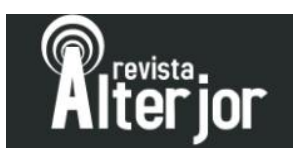

A partir desse diálogo de autores, é possível analisar a produção de vídeos curtos do Jornal Boca de Rua desenvolvida no período analisado. Observa-se que eles fazem parte de todo o contexto de produção de conteúdo do Jornal Boca de Rua apresentado nos capítulos anteriores, bem como são afetados pela troca de experiências no processo de observação participante.

\section{OS OLHOS DO BOCA E A PRODUÇÃO AUDIOVISUAL EM 2018}

Entre março e outubro de 2018 o grupo que participava do projeto Jornal Boca de Rua produziu uma série de dez vídeos curtos para sua página homônima do Facebook $^{18}$. A minha presença ${ }^{19}$ de certa forma movimentou e incentivou estas produções na medida em que eu já havia criado determinados vínculos com o grupo. Ainda que a página do Jornal Boca de Rua não siga um cronograma de postagens ou qualquer tipo de planejamento estratégico, definiu-se como "potencial para alto engajamento e alcance" vídeos curtos - idealmente com menos de um minuto, que, por abranger uma causa social relevante, já teriam um número de compartilhamentos significativos e por isso um alcance orgânico alto. Se, por um lado, essa visão de estratégia comunicacional não tenha sido pauta da reunião com seus termos técnicos específicos, por outro, a questão do tempo, da linguagem e do formato do vídeo foram definidos por integrantes do grupo ${ }^{20}$, que tinham diferentes maneiras de envolver-se com o projeto audiovisual:

Já no final da reunião, a Rosina pergunta ao grupo "tem como fazer um vídeo para divulgar a edição no face? O pessoal pareceu meio em

\footnotetext{
${ }^{18}$ Disponível em: http://facebook.com/jornalbocaderua. Acesso em agosto de 2019.

${ }^{19}$ Conforme nota da página 4 , "durante os trechos deste artigo que referem-se a experiências em que estive muito envolvida ou à análises essencialmente subjetivas oriundas da observação-participante, utilizo-me da primeira pessoa".

${ }^{20}$ Os primeiros movimentos nesse sentido ocorreram após a participação de dois integrantes do jornal em um programa cultural de entrevistas da TV na qual eu fazia estágio. Na ocasião, surgiu a ideia do que se chamou de TV Boca, que seria vinculada a um canal no Youtube e, ao contrário das produções audiovisuais anteriores que tematizaram o Jornal Boca de Rua, seria o caso de não envolver pessoas externas ao grupo. Como teste para este projeto maior, decidiu-se produzir vídeos com potencial para alto engajamento e alcance no Facebook, até então a única rede social alimentada pelo grupo
} 


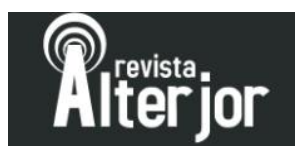

dúvida. Já tinha poucas pessoas e só homens. Ela pediu especificamente ao A. F. e ele topou. Aí o V. também quis. O resto do grupo se encaminhou para formar a fila da entrega do jornal enquanto nós três fomos para o pátio para decidir como faríamos a gravação. Fiz questão de que eles próprios me falassem como deveríamos gravar, onde, com qual linguagem e enquadramento. Assim que saímos o A. riu: "isso que é democracia, um anarca e um reaça falando juntos". "Tu quer gravar separado?", perguntou o vereador meio sem graça. "Claro que não, meu", respondeu A.. Aí o A. nos chamou pra gravar em um canto com mais luz. Vereador começa a falar como se estivesse em um telejornal. A. interrompe: "assim tá muito sério". [...] "Devia ter me avisado que a gola tava torta", disse o vereador pra mim depois que mostrei o vídeo pronto (DIARIO, julho, 2018).

O início das produções audiovisuais ocorreu no dia 14 de março de 2018. O momento de produção ocorria apenas após o término da reunião semanal e, portanto, após a entrega dos jornais impressos. O primeiro produto audiovisual, ao contrário dos demais, é marcado por uma certa impessoalidade. O uso do microfone lapela e o pedido do grupo para que fosse incluído o logo do jornal ao canto do vídeo tornaram-no esteticamente mais parecido com um produto de jornal tradicional e hegemônico. Repetiu-se o processo gramatical (VERÓN, 2006) já presente na diagramação do jornal impresso de assimilação de símbolos, produção de sentidos e reconhecimento no qual o jornalismo propriamente dito é identificado a partir de determinadas práticas e resultados imagéticos.

Os vídeos que evidenciam essa gramática de produção jornalística buscam divulgar a edição mais recente do jornal ou alguma matéria específica presente nela, conforme descrito na tabela a seguir: 


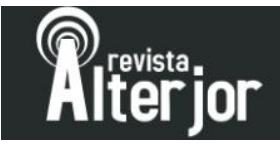

\begin{tabular}{|c|c|c|c|}
\hline Vídeo & Descrição & Tática & Elementos identitários \\
\hline $\begin{array}{l}\text { "Limpeza Urbana, } \\
\text { Limpeza } \\
\text { Humana" }\end{array}$ & \multirow[t]{2}{*}{$\begin{array}{l}\text { Descrição de parte do conteúdo } \\
\text { do jornal e anúncio da liberação } \\
\text { de uma nova edição. }\end{array}$} & \multirow[t]{2}{*}{$\begin{array}{l}\text { Fomentar nos } \\
\text { telespectadores curiosidade } \\
\text { em comprar a próxima } \\
\text { edição. }\end{array}$} & \multirow{3}{*}{$\begin{array}{l}\text { Mostrando-se e mostrando o que } \\
\text { o grupo é, no momento que } \\
\text { divulgam o projeto e o defendem } \\
\text { estão defendendo também a } \\
\text { existência do grupo. }\end{array}$} \\
\hline $\begin{array}{l}\text { Edição } 68 \text { do } \\
\text { Jornal Boca de } \\
\text { Rua }\end{array}$ & & & \\
\hline $\begin{array}{l}\text { Boca de Rua nas } \\
\text { eleições } 2018\end{array}$ & $\begin{array}{l}\text { Declaração de voto contra o } \\
\text { candidato de extrema-direita das } \\
\text { eleições presidenciais de } 2018 \text { - } \\
\text { na edição impressa o } \\
\text { posicionamento também está } \\
\text { presente. }\end{array}$ & $\begin{array}{l}\text { Posicionamento político em } \\
\text { defesa das minorias }\end{array}$ & \\
\hline \multirow[t]{4}{*}{$\begin{array}{l}\text { Ocupação Aldeia } \\
\text { Zumbi dos } \\
\text { Palmares }\end{array}$} & \multirow[t]{4}{*}{$\begin{array}{l}\text { Um dos integrantes do jornal, } \\
\text { que também é integrante da } \\
\text { ocupação, mostra o local. }\end{array}$} & \multirow[t]{4}{*}{$\begin{array}{l}\text { Busca pela representação } \\
\text { de si }\end{array}$} & $\begin{array}{l}\text { Apresentação como integrante } \\
\text { do Movimento Nacional da } \\
\text { População de Rua }\end{array}$ \\
\hline & & & $\begin{array}{l}\text { Escolha por iniciar o vídeo em } \\
\text { frente ao muro com os dizeres } \\
\text { "Direito à moradia e à cidade" }\end{array}$ \\
\hline & & & $\begin{array}{l}\text { A descrição imagética do espaço } \\
\text { em que estavam vivendo e a } \\
\text { forma como as pessoas que } \\
\text { aparecem estão se organizando } \\
\text { em grupo ou trabalhando }\end{array}$ \\
\hline & & & $\begin{array}{l}\text { Escolha de palavras e expressões } \\
\text { como "nossos amigos", "irmãos }\end{array}$ \\
\hline \multirow[t]{4}{*}{$\begin{array}{l}\text { Remoções em } \\
\text { Porto Alegre }\end{array}$} & \multirow[t]{4}{*}{$\begin{array}{l}\text { Descrição de algo que estava } \\
\text { acontecendo, explicação de } \\
\text { porquê é um problema e quais } \\
\text { alternativas estão sendo } \\
\text { encontradas }\end{array}$} & \multirow[t]{4}{*}{$\begin{array}{l}\text { Busca pela representação } \\
\text { de si }\end{array}$} & $\begin{array}{l}\text { Boné virado pra trás e jaqueta } \\
\text { desgastada }\end{array}$ \\
\hline & & & $\begin{array}{l}\text { Cenário com a sigla da Escola } \\
\text { Porto Alegre aparecendo }\end{array}$ \\
\hline & & & Linguagem: "na realidade" \\
\hline & & & Utilização de "nós" \\
\hline
\end{tabular}

Revista ALTERJOR

Grupo de Estudos Alterjor:Jornalismo Popular e Alternativo (ECA-USP)

Ano 10 Volume ol Edição 23 Janeiro-Junho de 2021

Avenida Professor Lúcio Martins Rodrig̉ues, 443, Cidade Universitária, São Paulo, CEP: 05508-020 


\begin{tabular}{|c|c|c|c|}
\hline $\begin{array}{l}\text { Bicicletas em } \\
\text { Porto Alegre }\end{array}$ & $\begin{array}{l}\text { Gravação "espontânea" realizada } \\
\text { pelo celular de um dos } \\
\text { integrantes e trata sobre uma das } \\
\text { pautas que estava em andamento } \\
\text { na época durante o } \\
\text { desenvolvimento da versão } \\
\text { impressa do jornal. A } \\
\text { legendagem foi necessária já que } \\
\text { na hora da captação não havia } \\
\text { um equipamento de áudio e o } \\
\text { barulho da rua atrapalhava o } \\
\text { entendimento. }\end{array}$ & $\begin{array}{l}\text { Fomentar nos } \\
\text { telespectadores curiosidade } \\
\text { em comprar a próxima } \\
\text { edição. }\end{array}$ & $\begin{array}{l}\text { Durante a entrevista, o integrante } \\
\text { do jornal que conversa com a } \\
\text { fonte - ainda que suas perguntas } \\
\text { não apareçam no corte final, } \\
\text { segura uma edição do Jornal } \\
\text { Boca de Rua de forma que seja } \\
\text { possível identificar a qual grupo } \\
\text { ele pertence. }\end{array}$ \\
\hline $\begin{array}{l}\text { Entrevista com } \\
\text { estudantes do } \\
\text { Colégio Monteiro } \\
\text { Lobato }\end{array}$ & $\begin{array}{l}\text { Relato dos estudantes sobre a } \\
\text { participação nas reuniões do } \\
\text { grupo e sobre a presença dos } \\
\text { integrantes do jornal na escola. }\end{array}$ & $\begin{array}{l}\text { Sensibilizar o público, } \\
\text { principalmente no que diz } \\
\text { respeito aos problemas que } \\
\text { o grupo já enfrentou com } \\
\text { estudantes universitários } \\
\text { que não dão retorno sobre } \\
\text { seus trabalhos. }\end{array}$ & $\begin{array}{l}\text { A presença constante dos } \\
\text { entrevistadores, tanto na fala } \\
\text { quanto com o corpo. }\end{array}$ \\
\hline \multirow[t]{2}{*}{$\begin{array}{l}\text { Entrevista com a } \\
\text { mãe do Ceco }\end{array}$} & \multirow[t]{2}{*}{$\begin{array}{l}\text { Apresentação da família do Ceco } \\
\text { e, com isso, uma homenagem } \\
\text { para ele. }\end{array}$} & \multirow[t]{2}{*}{$\begin{array}{l}\text { Sensibilizar o público para } \\
\text { que conheçam a história de } \\
\text { um dos mais antigos } \\
\text { membros do grupo que } \\
\text { faleceu. }\end{array}$} & $\begin{array}{l}\text { A utilização do colete do Boca e } \\
\text { falas como a do Zé: "o Boca de } \\
\text { Rua não é um jornal não, ele é } \\
\text { uma família"; além de sua } \\
\text { postura enquanto apresentador } \\
\text { do vídeo, que, a partir da fala, } \\
\text { guia o telespectador. }\end{array}$ \\
\hline & & & $\begin{array}{l}\text { Imagens iniciais do grupo } \\
\text { durante a distribuição do jornal }\end{array}$ \\
\hline $\begin{array}{l}\text { Fotografia e } \\
\text { população em } \\
\text { situação de rua }\end{array}$ & $\begin{array}{l}\text { Dias antes do lançamento do } \\
\text { livro do projeto extensionista da } \\
\text { UFRGS A Cara da Rua, na qual } \\
\text { pessoas em situação de rua têm } \\
\text { aulas de fotografia, }\end{array}$ & $\begin{array}{l}\text { Fazer com que os } \\
\text { telespectadores tenham } \\
\text { mais curiosidade em } \\
\text { comprar a próxima edição. }\end{array}$ & $\begin{array}{l}\text { O foco na pergunta que foge da } \\
\text { pauta: "O que representa para o } \\
\text { senhor estar no Jornal Boca de } \\
\text { Rua?" e o constante } \\
\text { enquadramento e fala de quem } \\
\text { filma o video. }\end{array}$ \\
\hline
\end{tabular}

A tática é, essencialmente, fomentar nos telespectadores curiosidade em comprar a próxima edição. É possível salientar que no momento em que os integrantes decidem mostrar-se em vídeo para divulgar o projeto, apresentam ao público o projeto em si. Isto é, defendem a existência do grupo propriamente dita.

Já nos vídeos em que há a intenção de reportar denúncias ou desenvolver notícias com fontes internas ou externas, as táticas e as marcações identitárias mudam. Opta-se pela escolha de palavras e expressões como "nossos amigos", "irmãos", "nós", a apresentação de si como integrante do Movimento Nacional da População de Rua, 


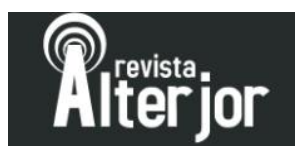

assim como determinados cuidados com o cenário dos vídeos. Em uma das produções, o grupo optou por realizar o início do vídeo em frente ao muro com os dizeres "Direito à moradia e à cidade". É feita a descrição imagética do espaço em que estavam vivendo e a forma como as pessoas que aparecem estão se organizando em grupo ou trabalhando. Também se observa a palavra "EPA", atrás de quem fala. EPA é a Escola Porto Alegre, na qual as pessoas em situação de rua são atendidas. Há uma disputa de discurso em jogo e, para os participantes do Jornal Boca de Rua, é importante serem reconhecidos e identificados enquanto pertencentes a estes espaços de militância, organização, trabalho e educação. Mostram-se em frente às câmeras, portanto, como querem ser vistos e também como se veem.

Aponta-se ainda que o grupo tende a fechar-se em relação a pessoas "de fora", isto é, utilizar como fonte prioritária - mas não única - os próprios constituintes do jornal. Suas experiências enquanto fontes primárias e testemunhais são valorizadas a partir dessa escolha editorial. Ainda assim, nos casos em que há a presença de fontes externas, essas são escolhidas de forma tática. No que diz respeito especificamente aos vídeos aqui analisados, estas fontes externas foram escolhidas pelos próprios integrantes que realizaram as captações dos vídeos e se, por um lado, não há nenhum representante do poder público, por outro lado, há uma ciclista, estudantes, familiares e um dos membros da ONG Alice. Pessoas presentes no dia a dia de quem as entrevistou, mas que, de forma mais ampla, contemplam a busca por formações de alianças e conferem sentido à identidade também de quem as entrevista. As referências encontradas nesta pesquisa no que diz respeito à construção do Jornal Boca de Rua como uma família aos seus integrantes são espelhadas nas escolhas por vinculações presentes nos vídeos.

A relação do jornal com a família aparece novamente quando eles contam como inseriram-se no grupo. Nesse sentido, utilizam as relações familiares também como método de divulgação do jornal e do projeto, indicando os aspectos afetivos presentes no grupo.

Eu vim aqui pro Boca através da minha irmã [...] Quando ela era do jornal, que que eu fazia? Eu vivia criticando "Eu não quero esse jornal 
m*..." [...] Só que depois eu mesma fui percebendo que aquele jornal era... foi tão importante pra ela, que eu acabei entrando. Porque depois eu vi "bah, não tenho emprego, o que que eu vou fazer? Vou pro jornal". E hoje eu to aqui no jornal. E agora eu não quero mais sair né (risos) já tive oportunidade de arrumar emprego, mas voltei de novo pro jornal. Quando eu cheguei fui bem aceita, fui bem recebida. Não teve assim um... as pessoas não me julgaram ou "ai, tu não vai ficar no jornal". Eu tenho uma filha minha que só quer completar 18 anos pra ser jornalista, vim vender jornal também [...] Olha, pra mim significa tudo o jornal. O Boca de Rua é a minha família, né? A parte da minha família que eu não tenho. [...] E hoje eu consegui sair da rua, só que eu saí da rua, mas a rua não saiu de mim. Continuo na rua porque tenho amigos que tão na rua. Mas não na rua pra morar na rua assim, sabe? Eu gosto da rua, mesmo que eu tenha a minha casa, mas eu tenho que estar sempre na volta dos meus amigos que tão na rua né (M., 2019).

O espaço do jornal e a interação entre os seus integrantes, a partir desta perspectiva, constitui-se também enquanto uma possibilidade de vinculação afetiva e financeira com menos julgamentos. Afirmações como "a rua não saiu de mim" (Ibidem, 2019) e "todo mundo nasce repórter" (DIARIO, jul, 2019) mostram que a possibilidade de associar-se à profissão de jornalista. Citada diversas vezes e performatizada em parte dos vídeos, torna-se tática no sentido de utilizar-se da figura do senso comum de "pessoa em situação de rua" para se autorrepresentar enquanto profissionais da comunicação, dotados de inteligências e conhecimentos próprios.

A partir do desenvolvimento destes vídeos, esse objetivo de autoafirmarem-se e autorrepresentarem-se também pôde ser analisado a partir da escolha por enquadramentos nos quais o "mostrar-se em cena" - a partir de selfies e movimentos de câmera - tornava-se característico da filmagem. Construiu-se, assim, um elemento narrativo de pertencimento ao vídeo e, portanto, ao grupo. Essa tática identitária é um modo de revelar inclusive quem está fazendo o trabalho de cinegrafista, por trás das câmeras, dando ares de gravação de bastidores.

Ainda que se trata de vídeos em que o "assunto" da imagem não precisaria ser os membros do jornal, em diferentes momentos eles colocam-se espontaneamente em frente à câmera ou identificam o vídeo com o próprio jornal, com uma camisa ou bandeira. Há a presença constante dos entrevistadores, tanto na fala quanto com o corpo. 


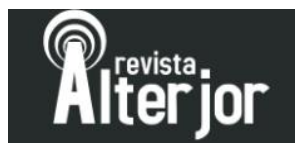

Outro elemento salientado é que, nas duas ocasiões em que os integrantes do grupo realizaram filmagens de forma totalmente autônoma e fora do espaço de reunião de pauta, utilizaram do celular gravando na vertical, com diversas interferências no áudio e pouca estabilidade na imagem, barulhos da rua e fuga dos enquadramentos de plano médio majoritariamente escolhidos para as gravações internas e acompanhadas. Essas gravações em ambientes menos formais que a reunião de pauta, estimularam o uso da criatividade e espontaneidade, para além de formatos pré-estabelecidos.

Os membros do Jornal Boca de Rua, individualmente, também relataram o porquê de valorizarem o grupo enquanto um espaço de trabalho e não apenas um coletivo de pessoas em situação de rua que querem ter suas pautas ouvidas pela população. Foram citadas a possibilidade de autorrepresentação e reivindicação em relação ao poder público, além da construção de mais respeito em relação aos demais moradores de Porto Alegre:

Na verdade eu preciso de uma câmera, se alguém puder doar uma pra nós. Preciso entrevistar a galera da rua, acho que pode ficar bem interessante. Eu tenho muito conhecimento da rua sabe, então eu acho que o pessoal vai ser abrir bem mais né? Conversar mais com a gente. Ninguém vai ficar encabulado de chegar pra conversar e dar uma entrevista. [...] Porque o Boca fala toda a verdade da rua né. Fala o que que se passa com a gurizada da rua aí, se tão sendo agredidos pela polícia, pelos guardas municipais. Os cara chegam juntando documento, jogando as coisas deles tudo fora (D., 2019).

Ah, é importante ser jornalista. Porque as vezes as pessoas dizem assim "ah, ela é jornalista e moradora de rua?" (tom de desdenho) Mas eu quero que o pessoal, desses que compram, continuem comprando e acreditando que nós moradores de rua somos capazes de fazer um jornal (M., 2019).

Os integrantes do Jornal Boca de Rua querem ser assimilados às suas particularidades e suas vivências individuais, para além do pertencimento ao grupo, que também constitui-se como um fator definidor da construção das pessoas que são e do trabalho que realizam. Ainda que o elemento de geração de renda ainda esteja bem presente em suas intencionalidades e nas discussões do grupo, é perceptível o objetivo de mudança de paradigma e sensibilização de quem os assiste. 


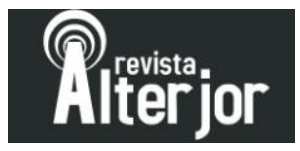

O recorte bastante específico da produção audiovisual do Jornal Boca de Rua e seu desenvolvimento aqui analisado possibilitou a compreensão do Jornal Boca de Rua essencialmente enquanto grupo de trabalho e geração de renda, que utiliza-se da afirmação das suas identidades minoritárias de forma tática e subversiva. Mesmo após quase dois anos de envolvimento com o grupo, parecia tratar-se de produções de conteúdo audiovisuais movidas essencialmente por questões identitárias e ideológicas que geravam pertencimento com o grupo; mas ao desenvolver este estudo e ouví-los também de forma individual, foi possível adicionar o aspecto tático de seus discursos e produções.

\section{CONSIDERAÇÕES FINAIS}

A produção de conteúdo audiovisual para as redes sociais do Jornal Boca de Rua analisada no presente estudo atravessa a construção da identidade e do pertencimento das pessoas em situação ou vivência de rua que atuam no grupo de modo a evidenciar a construção de vínculos e alianças e de discursos identitários de forma tática (CERTEAU, 1998). O processo de produção dos vídeos permitiu a experimentação dos integrantes do jornal em termos de formato, conteúdo e estratégias de autorrepresentação e sensibilização dos telespectadores, bem como as táticas de disputa por visibilidade.

Nesse sentido, a construção de identidade e pertencimento ocorre de maneiras sobrepostas e complementares não apenas no âmbito individual, mas em aspectos coletivos. Em parte da produção audiovisual analisada há vídeos com estética e enquadramentos mais jornalísticos, enquanto, em outros, as figuras de cinegrafista, entrevistador e entrevistado se misturam com maior facilidade; há uma tática de "mostrar-se em cena" que integra a narrativa. Observa-se esse processo de perceber-se e ser percebido culturalmente enquanto profissionais da comunicação e, ao mesmo tempo, como parte integrante de um grupo minoritário que reivindica melhorias.

A tática aplicada a alguns dos vídeos foi voltada justamente para a busca de autorrepresentação do grupo e de seus indivíduos. Ao mostrar-se ao público em vídeo, os membros do Jornal Boca de Rua exemplificaram suas singularidades a partir de vestimentas, oratória, gírias e movimentos com o corpo e escolhendo cenários e adereços que ajudassem a identificá-los como membros daquele grupo. 


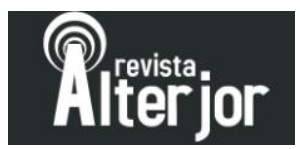

Constata-se ainda que o Jornal Boca de Rua é um importante elemento de criação de vínculos afetivos e que a valorização do projeto enquanto espaço de trabalho possibilitou que parte do grupo inclusive deixasse a situação de rua. A citação por mais de uma pessoa em convidar membros da família para participar do grupo também mostra essa vinculação subjetiva, assim como as escolhas das fontes nos produtos audiovisuais.

As táticas e estratégias de visibilidade e afirmação de identidades perpassam a disputa histórica nas quais grupos minoritários buscam espaço simbólico na esfera pública. Os formatos de produção de conteúdo possuem suas respectivas potencialidades nesse sentido, como verificou-se nas produções de vídeos curtos para as redes sociais do Jornal Boca de Rua.

\section{REFERÊNCIAS}

ALVARENGA, Clarisse; Hijiki, Rose Satiko. 2006. "De dentro do bagulho: o vídeo a partir da periferia". In: Ferrari, F; Hijiki, R. S. et al. (orgs.). Sexta Feira 8 Periferia. São Paulo: Editora 34.

ALVES, Marcia Nogueira; FONTOURA, Mara; ANTONIUTTI, Cleide Luciane. Mídia e produção audiovisual: uma introdução. Curitiba: Ibpex, 2008.

APRESENTAÇÃO. In: Prefeitura de Porto Alegre. Disponível em: http://www2.portoalegre.rs.gov.br/fasc/default.php?p_secao=56. Acesso em: ago, 2019.

ARAÚJO, Juliano José de. Cineastas indígenas, documentário e autoetnografia: um estudo do projeto vídeo nas aldeias. Campinas: Programa de Pós-Graduação em Multimeios do Instituto de Artes da Universidade Estadual de Campinas - Unicamp, 2015.

ARÁN, Márcia; PEIXOTO, Carlos Augusto Jr. Vulnerabilidade e vida nua: bioética e biopolítica na atualidade. Revista Saúde Pública. Universidade do Estado do Rio de Janeiro, 2007.

AZEVEDO, Ana. Autorrepresentação em Vídeo: O Eu como Espessura, a Experiência como Ritmo. Congresos de GKA, Congreso Internacional de Cultura Visual, 2017.

BAUMAN, Zygmunt. Identidade: entrevista a Benedetto Vecchi. Rio de Janeiro: J. Zahar Editor, 2005.

BICICLETAS em Porto Alegre. In: Facebook. Disponível em: <https://www.facebook.com/watch/?v=2055955188011985> Acesso em: set 2019.

BOCA de Rua nas eleições 2018. In: Facebook. Disponível em: <https://www.facebook.com/watch/?v=1922979554459963> Acesso em: set 2019.

CENTRO DE ATENÇÃO PSICOSSOCIAL. In: Prefeitura de Porto Alegre. Disponível em: https://alfa.portoalegre.rs.gov.br/carta-de-servicos/centro-de-atencao-psicossocial. Acesso em: ago, 2019.

CENTRO POP. In: Proteção Social Especial - Ações de Média Complexidade. Disponível em: http://www2.portoalegre.rs.gov.br/fasc/default.php?p_secao=139. Acesso em: ago, 2019.

Revista ALTERJOR

Grupo de Estudos Alterjor:Jornalismo Popular e Alternativo (ECA-USP)

Ano 10 Volume Ol Edição 23 Janeiro-Junho de 2021

Avenida Professor Lúcio Martins Rodrig̉ues, 443, Cidade Universitária, São Paulo, CEP: 05508-020 


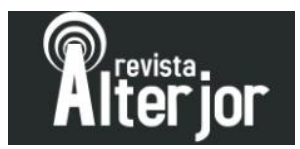

CERTEAU, Michel de. A invenção do cotidiano. ed. 3. Petrópolis: Editora Vozes, 1998.

COMPOSIÇÃO DE REDUÇÃO DE DANOS. In: Atenção Básica do RS. Disponível em: $<$ https://atencaobasica.saude.rs.gov.br/composicoes-de-reducao-de-danos> Acesso em nov 2019.

EDIÇÃO 68 do Jornal Boca de Rua. In: Facebook. Disponível em: <https://www.facebook.com/watch/?v=2126966287577541> Acesso em: set 2019.

ENTREVISTA com a mãe do Ceco. In: Facebook. Disponível em: <https://www.facebook.com/watch/?v=219778995355117> Acesso em: set 2019.

ENTREVISTA com estudantes do Colégio Monteiro Lobato. In: Facebook. Disponível em: <https://www.facebook.com/watch/?v=2113790592228444> Acesso em: set 2019a.

FIGUEIREDO, Patrícia. Brasil registra mais de 17 mil casos de violência contra moradores de rua em 3 anos. In: G1. Disponível em: <https://g1.globo.com/sp/saopaulo/noticia/2019/06/17/brasil-registra-mais-de-17-mil-casos-de-violencia-contra-moradoresde-rua-em-3-anos.ghtml> Acesso em: out 2019.

FOTOGRAFIA e população em situação de rua. In: Facebook. Disponível em: <https://www.facebook.com/watch/?v=1963952550565384> Acesso em: set 2019.

HALL, Stuart. A identidade cultural na pós-modernidade. $11^{a}$ ed. Tradução Tomaz Tadeu da Silva. Rio de Janeiro: DP\&A, 2006.

LIMPEZA Urbana, Limpeza Humana. In: Facebook. Disponível em: <https://www.facebook.com/watch/?v=2036734089934095> Acesso em: set 2019.

MALDONADO, Aberto Efendy. Transmetodologia, cidadania comunicativa e transformação tecnocultural. In: Intexto. Porto Alegre, UFRGS, n. 34, p. 713-727, set./dez. 2015.

OCUPAÇÃO Aldeia Zumbi dos Palmares. In: Facebook. Disponível em: <https://www.facebook.com/watch/?v=2047202108887293> Acesso em: set 2019.

PAIVA, Raquel. Mídia e políticas de minorias. In: BARBALHO, Alexandre; PAIVA, Raquel (orgs.). Comunicação e cultura das minorias. São Paulo: Paulus, 2005.

REMOÇÕES em Porto Alegre. In: Facebook. Disponível em: <https://www.facebook.com/watch/?v=951007185096861> Acesso em: set 2019.

SCHUCH, Patrice; GEHLEN, Ivaldo. A "Situação de rua" para além de determinismos:

explorações conceituais. In: A Rua em Movimento: debates acerca da população adulta em situação de rua na cidade de Porto Alegre. Didática Editora do Brasil: Belo Horizonte/MG, 2012.

SCHUCH, Patrice; GEHLEN, Ivaldo; SANTOS, Simoe Ritta dos (org). População de rua: políticas públicas, práticas e vivências. 1 ed. Porto Alegre: CirKula, 2017.

SODRÉ, Muniz. Por um conceito de minoria. In: BARBALHO, Alexandre; PAIVA, Raquel (orgs.). Comunicação e cultura das minorias. São Paulo: Paulus, 2005.

VERÓN, Eliseo. Os públicos entre produção e recepção: problemas para uma teoria do reconhecimento. In: ABRANTES, José Carlos; DAYAN, Daniel (org). Televisão: das audiências aos públicos. Lisboa: Livros Horizonte, 2006. p. 113-126. 